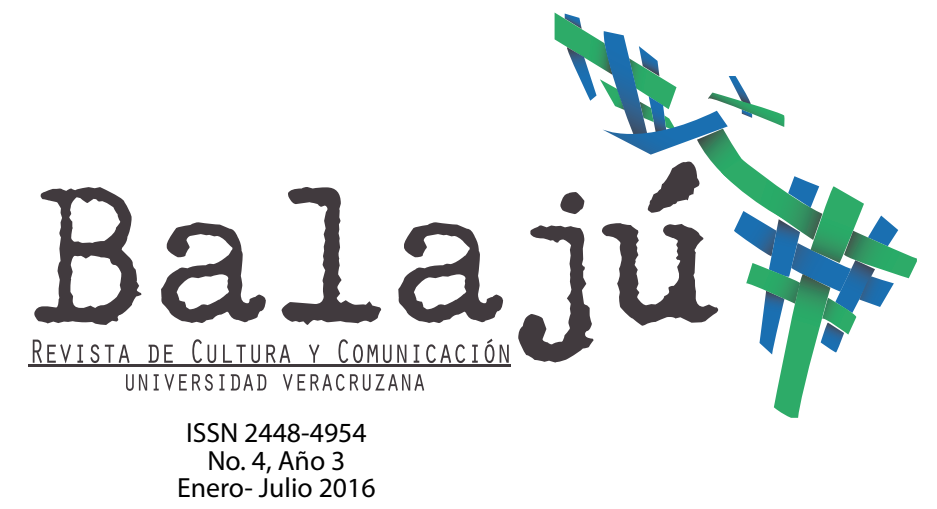

\title{
La sombra de Martín Luis Guzmán. Política, historia y literatura como testimonio
} Eduardo Torres Alonso

Universidad Nacional Autónoma de México etorres.alonso@gmail.com

\section{RESUMEN}

Este artículo revisa el vínculo que existe entre la literatura y la política. Para esto, se ha seleccionado al escritor y político mexicano Martín Luis Guzmán y a una de sus obras más representativas: La sombra del caudillo. Esta novela ilustra las formas para alcanzar, mantener y ampliar el poder político en una época de caudillos, intrigas e ilusiones, angustias e imaginación; aunada a la intensa y polifacética vida de su autor, nos brindan una descripción clara del sistema político mexicano del siglo XX.

\begin{abstract}
This article seeks to review the link that exists between literature and politics. In order to do so, it examines the writer and Mexican politician Martín Luis Guzmán and one of his most representative works: La sombra del caudillo. This novel illustrates ways to achieve, maintain and expand political power in an era of warlords, intrigues and illusions, fears and imagination; coupled with the intense and multifaceted life of its author, it offers a clear description of the Mexican political system of the twentieth century.
\end{abstract}

\section{PALABRAS CLAVES}

literatura mexicana, Revolución mexicana, política, historia, Martín Luis Guzmán.

\section{KEYWORDS}

Mexican literature, Mexican Revolution, politics, history, Martín Luis Guzmán. 


\section{La sombra de Martín Luis Guzmán. Política, historia y literatura como testimonio}

Eduardo Torres Alonso ${ }^{1}$

\section{Introducción}

Isaiah Berlin señaló que para realizar análisis político no sólo debe recurrirse a las herramientas propias de la disciplina política, sino que es menester tomar otras que ayuden a complementarlo y amplíen los horizontes de reflexión. Muestra de ello es su trabajo Pensadores rusos. Próximo a esta idea, se encuentra el historiador Edmundo O' Gorman, al sostener que la historia se conoce mejor a través de la novela histórica que de la misma historiografía. La novela no se limita a dar cuenta de los hechos comprobables del pasado sino que, con los elementos que la ficción le añade al discurso histórico, nos procura una visión más amplia y más profunda de la realidad a la que refiere. Es así que, de forma implícita en el caso de Berlin y explícita en O’ Gorman, se reconoce la importancia de la literatura para nutrir los trabajos académicos.

En el convulso México de inicios del siglo XXI, la Revolución fue la expresión armada de un proceso cuyo objetivo fue construir un nuevo andamiaje institucional que ofreciera certidumbre a todos e integrara a los excluidos. Por su naturaleza, dimensiones, actores y discursos, el movimiento armado ha sido objeto de múltiples trabajos, desde académicos hasta eminentemente literarios. La constante en ellos, sin embargo, es la descripción de las acciones populares y militares, así como de las transformaciones en los diversos ámbitos de la vida social que generó. Más aún, una vez iniciada la institucionalización de la Revolución, nuevos protagonistas emergieron aunque, al igual que en el periodo violento, el objetivo fue alcanzar, mantener y expandir el poder.

La prosa y el verso, el ensayo, el cuento, la poesía, en fin, la novela sirvieron para difundir y criticar la edificación de un México que intentaría cumplir con las demandas de la lucha, puestas ya en el armazón fundamental, múltiple y polivalente de la República: la Constitución de 1917.

En este trabajo se revisa el vínculo que existe entre la literatura y la política, entre la imaginación y el poder. Para ello, se ha seleccionado al escritor y político mexicano Martín Luis Guzmán Franco y a una de sus obras más representativas: La sombra del caudillo. En esta y en la biografía de su autor, se ilustran las formas de hacerse del poder,

1. Licenciado en Ciencias Políticas y Administración Pública por la FCPyS, UNAM. Actualmente se desempeña como Secretario técnico del Seminario Universitario de Estudios sobre Sociedad, Instituciones y Recursos de la Universidad Nacional Autónoma de México. 
mantenerlo y ampliarlo, en una época de caudillos, generales, intrigas y, también, ilusiones, angustias e imaginación.

\section{Aproximación biográfica}

\section{Los inicios}

En la calle La Libertad, marcada con el número 5, de la capital del estado de Chihuahua, nació Martín Luis Guzmán Franco, el 6 de octubre de 1887. Su padre, de origen yucateco, fue el coronel de infantería Martín Luis Guzmán Rendón. Su madre, Carmen Lucrecia Franco Terrazas, chihuahuense. Tuvo cinco hermanos: Carmen Isabel, Manuel Demetrio, Mercedes Lucrecia, María Cristina y Francisco Lamberto, quien murió poco después de nacer.

Antes de cumplir dos meses de nacido, Martín Luis, junto con su familia, dejó el norte del país para radicar en la Ciudad de México, debido a que su padre había sido designado director del Departamento Estadístico de Trámite Administrativo de Libros y Listados del Colegio Militar, en donde, además, se desempeñó como profesor de táctica de infantería y de caballería. Su nueva casa estuvo en la 2a. Calle de la Joya número 242, ubicada en la prefectura de Tacubaya. Este sitio fue en donde el futuro escritor se reconocería nacido a la vida del espíritu.

A los 11 años de edad, ya más cerca de los 12, vuelve a mudarse, ahora al puerto de Veracruz. Ahí, el joven Guzmán, se acercó a las ideas liberales, escuchando hablar de Guillermo Prieto y de Benito Juárez. Tres años después, en 1901, emprendió su primera labor editorial: junto con Feliciano Prado editó La Juventud, su primera revista, de publicación quincenal, que tuvo una vida no mayor a seis meses.

Martín Luis Guzmán se refiere a la influencia que su padre ejerció en su formación. La orientación en sus lecturas fue fundamental y logró con ello alejarse de sus inclinaciones religiosas, que provenían de su formación en escuelas confesionales. Se acercó a Los mil y un días de Juan de Dios Peza, a los corridos populares ilustrados por José Guadalupe Posada, al poeta latino Juvenal y, por supuesto, a la prensa de la época. Leyó El Decamerón de Giovanni Boccaccio y Los miserables de Víctor Hugo; México a través de los siglos de Vicente Riva Palacio, El contrato social de Juan Jacobo Rousseau y Electra de Benito Pérez Galdós; en fin, se nutrió de buena y variada literatura. ${ }^{2}$

A su regresó a la capital de la República, volvió a vivir en Tacubaya. Se inscribió en la positivista Escuela Nacional Preparatoria (ENP),

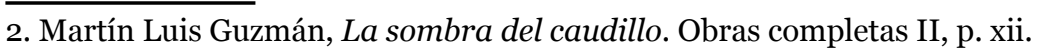


invento del alumno de Augusto Comte, Gabino Barreda, cuya sede era el antiguo Colegio Mayor de San Ildefonso. Guzmán estudió de 1904 a 1908 y después se matriculó en la carrera de jurisprudencia, obteniendo el correspondiente título de abogado en 1913.

$\mathrm{Su}$ primer acercamiento con el poder, acaso en extremo breve, ocurrió en 1912. El 16 de septiembre los alumnos de la ENP decidieron homenajear a los héroes de la Independencia nacional con tres actos: una procesión de antorchas, una velada literaria y musical en el Teatro Arbeu y un homenaje al licenciado Francisco Primo de Verdad y Ramos. Antes de concretar su iniciativa consiguieron, como era la norma, la aprobación gubernamental. En este homenaje, el joven Guzmán debuta como orador al pronunciar un discurso sobre José María Morelos y Pavón. Ese acto y las relaciones que entabló en esa coyuntura le abrirían, sin saberlo, las puertas de Palacio Nacional años después: fue amigo, confidente y defensor de los "hombres fuertes de México". Recuérdese la defensa que hizo, junto con Agustín Yáñez, de Gustavo Díaz Ordaz después del oscuro dos de octubre de 1968.

Siendo aún estudiante, Martín Luis Guzmán se casó, el 24 de julio de 1909, con Ana West Villalobos, hija del inglés William West, quien había llegado a México para trabajar en la construcción de las vías férreas en el istmo de Tehuantepec. El mismo año en que contrajo matrimonio, fue designado por su antiguo maestro -el escritor y en ese entonces subsecretario de Relaciones Exteriores Victoriano Salado Álvarezcanciller del consulado en Phoenix, Arizona, en Estados Unidos. Al asumir el cargo, tuvo que suspender sus estudios universitarios. Para agosto ya se encontraba en esa población. Sin embargo, una noticia inesperada lo hizo regresar a México: el crítico estado de salud de su padre.

El coronel Guzmán Rendón yacía en el hospital Miguel Salas, después de una reyerta con un grupo de revolucionarios, cerca de la población de Pedernales, en el Cañón de Malpaso, Chihuahua, en noviembre de 1910. Guzmán viajó a México para despedirse. Después de este suceso, dejó la diplomacia y se dirigió con su familia a la Ciudad de México, donde se reinscribió en la Escuela Nacional de Jurisprudencia. Fue profesor en la Escuela Superior de Comercio y trabajó como bibliotecario en la Escuela de Altos Estudios. Es en este momento cuando Martín Luis Guzmán participa en los trabajos del Ateneo de la Juventud e inicia su actividad política: fue nombrado delegado por Chihuahua en la Convención Nacional del Partido Liberal Constitucionalista. ${ }^{3}$

Al conocer los sucesos de la Decena Trágica (del 9 al 19 de febrero de 1913), varias personas, entre ellas Guzmán, publicaron El Honor

3. Ibid., pp. xviii-xix 
Nacional, periódico opositor que fue cerrado por instrucciones del golpista y usurpador Victoriano Huerta, en mayo de 1913. Además, junto con Alberto J. Pani, distribuyó propaganda subversiva hasta que los cercó la policía secreta. En esta atmósfera poco propicia para la libertad, decidió irse al norte del país y acercarse al constitucionalismo. Guzmán recuerda este episodio en su libro Febrero de 1913. Salió del puerto de Veracruz rumbo a Estados Unidos, para unirse a los revolucionarios. Venustiano Carranza, el "Barón de Cuatrociénegas", lo designó Oficial Mayor del gobierno de Sinaloa.

Cuando ocurrieron las discrepancias entre Carranza y Francisco Villa, en 1914, Guzmán optó por las fuerzas del líder de la División del Norte, de quien logró ser íntimo colaborador. Esta cercanía le permitió redactar, tiempo después, Memorias de Pancho Villa, con un vocabulario reducido pero muy expresivo. ${ }^{4}$

\section{Los exilios}

Debido a los problemas políticos del país y sus maltrechas relaciones con los grupos revolucionarios, Guzmán, que ya tenía el grado de coronel que le habían otorgado Lucio Blanco y Francisco Villa, sale hacia Estados Unidos, y de allí a Europa.

Una vez reunido con su familia en Arizona, probó suerte en Nueva York y, después, todos se dirigieron a París, en donde coincidieron con Diego Rivera. En 1915, llegaron a Madrid y, junto con Alfonso Reyes y Jesús T. Acevedo, formaron una comunidad mexicana en el exilio, teniendo como punto de reunión un edificio de la calle de Torrijos 14 Duplicado.

De la mano con Reyes escribe, bajo el seudónimo "Fósforo", la sección cinematográfica "Frente a la pantalla", en la revista España, dirigida por José Ortega y Gasset. Es probable, según Alfonso Reyes, que esa columna haya iniciado la crítica cinematográfica en lengua española. ${ }^{5}$ En el Centro de Estudios Históricos de Madrid, en la capital de la península ibérica, Guzmán se dedicó a la redacción de La querella de México, publicada por Imprenta Clásica Española, en 1915, conocida en México 40 años después. Vuelve a Nueva York en 1916, en donde abre un Book Department, en el número 42 de Broadway, retoma su labor como articulista en La Revista Universal y funge como director de $E l$ Gráfico, ambos publicados en español, en Manhattan.

4. Hugo Gutiérrez Vega, "Notas sobre la novela de la Revolución (III de VI)", La Jornada semanal. 
A su retorno a México, en 1919, año de luto para los revolucionarios por la muerte de Emiliano Zapata y de Felipe Ángeles, trabajó en el periódico El Heraldo de México como jefe de la sección editorial.

Cuando Adolfo de la Huerta le entregó el poder presidencial a Álvaro Obregón, en 1920, un antiguo amigo de Guzmán, Alberto J. Pani, fue designado secretario de Relaciones Exteriores e invitó a aquel a encargarse de la secretaría particular. En este mismo año, se publicó $A$ orillas del Hudson, libro de análisis histórico y político de México. Poco después, Guzmán fundó el diario El Mundo y fue elegido diputado a la XXX Legislatura de la Cámara de Diputados por el Partido Cooperativista Nacional, en 1922, representando al sexto distrito electoral de la Ciudad de México. Su suplente fue Severino Bazán.

Una vez iniciada la sucesión presidencial de Obregón, Guzmán decidió salir nuevamente del país, en 1923. Su cercanía con Adolfo de la Huerta, uno de los aspirantes a la presidencia y organizador de una revuelta contra el gobierno, lo había colocado en una situación riesgosa. Ambos coincidían en uno de los principios revolucionarios: la no reelección. Atrás quedaron la empresa periodística El Mundo, una radiodifusora comercial, la curul en la Cámara de Diputados y una posición relevante y polémica en el movimiento que se oponía a la elección de Calles. ${ }^{6}$

En este exilio de nuevo en Madrid, el más largo y profundo -de mayo de 1925 a abril de 1936, con una breve estadía en París, de agosto de 1926 a octubre de 1927-, escribió en varios periódicos y formó parte de la dirección de algunos de ellos, como El Sol y La Voz. Participó en la política española y portuguesa: asistió a las tertulias republicanas en el Café Regina, fue confidente y colaborador de Manuel Azaña y brindó ideas para derrocar al presidente Antonio de Oliveira Salazar. Tan próxima sintió a España que decidió adoptar la nacionalidad de aquel país. Si sumamos los dos exilios, estuvo fuera de México casi dos décadas.

Los últimos años de la década de los veinte y los primeros de los treinta fueron muy productivos para él: salieron a la luz El águila y la serpiente (1928), La sombra del caudillo (1929), Aventuras democráticas (1931), Mina el mozo: héroe de Navarra (1932), que después se titulará Javier Mina, héroe de España y de México que, dicho sea de paso, es la biografía más exhaustiva que se ha escrito sobre este personaje, y publicó Filadelfia, paraíso de conspiradores y otras historias noveladas (1933). Martín Luis Guzmán practicó el arte de rescatar vidas apasionadas de la frágil memoria del tiempo.7

Previa búsqueda de garantías, otorgadas por el presidente

6. Susana Quintanilla, “El águila y la serpiente, de Martín Luis Guzmán”, Letras Libres.

7. Emilia de Zuleta, Historia de la crítica española contemporánea, p. 308. 
Lázaro Cárdenas y transmitidas por Francisco J. Múgica, secretario de Comunicaciones, regresó a México en 1936 y se dedicó al periodismo en El Universal. Publicó, en 1938, El hombre y sus armas, primera parte de las Memorias de Pancho Villa, y en 1946 apareció Kinchil, nombrada después Maestros rurales.

\section{El regreso}

Ya en México, en 1937, junto con su amigo, el transterrado español, Rafael Jiménez Siles, Guzmán fundó Edición y Distribución Ibero-Americana de Publicaciones, S. A. Tres años después, circuló Romance, Revista Popular Hispanoamericana y, en 1942, Tiempo, Semanario de la Vida y la Verdad. La Compañía General de Ediciones, su otra aventura como editor, se concretó en 1949.

$\mathrm{Al}$ iniciar la segunda mitad del siglo XX, Guzmán vive otro periodo altamente productivo en materia editorial: en 1958, se edita Muertes históricas; un año después, aparece Islas Marías, novela y drama; en 1961, la Compañía General de Ediciones publicó sus obras completas y Pábulo para la historia; dos años después, aparecieron Febrero de 1913 y Necesidad de cumplir las leyes de Reforma y, en 1964, Crónicas de mi destierro.

El 22 de diciembre de 1976, en sus oficinas de la revista Tiempo, ubicadas en la calle de Barcelona número 32, en la colonia Juárez de la Ciudad de México, Martín Luis Guzmán, "el escultor de la prosa”, como lo llamó Octavio Paz, falleció por la noche, de un infarto al corazón, a los 89 años. Fue velado en el Palacio de Bellas Artes e inhumado en el Cementerio Español, junto a su padre.

\section{El escritor de lo prohibido}

\section{El tema}

Recordemos: la Revolución mexicana fue un proceso sociocultural y político-militar complejo y confuso, cuyo fin puede localizarse con la promulgación de la Constitución de 1917; se caracterizó por enfrentamientos entre clases sociales y tuvo expresión a través de la lucha contra los aparatos militares y políticos del antiguo régimen. ${ }^{8}$ Asimismo, fue un "proceso de renovación en los ámbitos culturales, educativos e

8. Javier Garciadiego, “Los intelectuales y la Revolución mexicana”, Carlos Altamirano (dir.), Historia de los intelectuales en América Latina. II Los avatares de la "ciudad letrada" en el siglo XX, p. 31. 
intelectuales". ${ }^{9}$

Este movimiento heterogéneo dio a la literatura un nuevo género: la novela de la Revolución que abarca: “... el conjunto de obras narrativas [...] inspiradas en las acciones militares y populares, así como en los cambios políticos y sociales que trajeron consigo los diversos movimientos (pacíficos y violentos) de la Revolución”. ${ }^{10}$

La sombra del caudillo, publicada en 1929, se inscribe dentro de este género y conjunta dos momentos históricos: el primero, acaecido durante el gobierno de Álvaro Obregón al comienzo de la sucesión presidencial, durante el cual Adolfo de la Huerta decide participar en el proceso para ocupar la máxima magistratura, en 1923. El segundo, durante el cuatrienio de Plutarco Elías Calles, cuando el general Francisco Serrano, candidato a la presidencia de la República, fue asesinado el 3 de octubre de 1927, junto con varios de sus partidarios, en Huitzilac, cerca de Cuernavaca. ${ }^{11}$ La novela, en tono trágico, muestra lo que se guarda en las cuevas del México revolucionario: el ciclo permanente de la búsqueda del poder.

Considerando el valor testimonial de La sombra del caudillo, el carácter de la novela se acentúa y se aproxima a la función de la crónica; $;{ }^{12}$ incluso, podemos señalar, su carácter híbrido de novela, relato histórico y texto autobiográfico es, en suma, un testimonio de los hechos y una denuncia de la inmoralidad pública. La novela ha convertido a aquel hecho en un episodio relevante para entender la lucha por el poder. En la fecha del asesinato, Martín Luis Guzmán estaba en España. Al leer la noticia en El Universal, su indignación fue tal que decidió protestar escribiendo.

Había estado planeando una trilogía que haría un resumen de la vida política de México. El primer volumen había de tratar de una manera novelística de la derrota de Carranza por Obregón. La segunda de la asonada delahuertista y la tercera del régimen callista y sus maquinaciones políticas. Cuando leí el reportaje sobre la matanza de Serrano en El Universal, decidí emplear esto junto con algunas de mis experiencias delahuertistas y me puse a escribir el segundo volumen inmediatamente. Me sentí hondamente conmovido por lo que había leído. ${ }^{13}$

9. Idem.

10. Antonio Castro Leal, La novela de la Revolución mexicana, p. 17.

11. Benjamín Salvo Aguilera, "La sombra de Martín Luis Guzmán”, Cuadernos Americanos, p. 214.

12. John S. Brushwood, México en su novela. Una nación en búsqueda de su identidad, p. 347.

13. F. Rand Morton, Los novelistas de la Revolución mexicana, p. 122 
En un inicio esta novela fue publicada por entregas en los periódicos La Opinión, La Prensa y El Universal, que circulaban en Los Ángeles, en San Antonio y en el Distrito Federal, respectivamente, recurriendo a una técnica típica de los escritores del siglo XIX. ${ }^{14}$ Sin embargo, no hay que considerar que las entregas aparecidas en los periódicos sólo fueron organizadas e integradas en un volumen para, así, estructurar la novela. De las 35 entregas originales, Guzmán eliminó siete y agregó un capítulo final. El Universal interrumpió, de forma definitiva en octubre de 1929, la publicación de las entregas de La sombra del caudillo, cuando debía haber aparecido el capítulo titulado "Los boletines de El Gran Diario". ${ }^{15}$ Si bien, esta acción privó a los lectores de ese periódico de conocer el final de la ficción, ellos ya lo sabían: la sucesión presidencial de 1927-1928. ${ }^{16}$ La Opinión y La Prensa completaron la serie en noviembre de 1929.

La novela está construida mediante una sucesión de cuadros donde se manifiestan el mal y sus trampas. Traigamos a nuestros ojos una de sus escenas para confirmar lo dicho. Ahí está el policía Zaldívar, torturador de Axkaná González, que es llevado ante el general Aguirre, que le reclama los tormentos de su partidario. No hay brutalidad en el trato. La sutileza es la característica. Axkaná bebió tequila hasta el colapso. Al general Aguirre le basta con pedir una botella de cognac y otra de tequila, así como papel y pluma para la confesión. El acusado sabe su destino: beber tanto alcohol como pueda y reconocer lo hecho contra el amigo de Aguirre. Firma una confesión amplia y pide protección. Se pacta. No hay amenaza sino disuasión. ${ }^{17}$ Esta escena nos hace pensar que la dominación viste con más prendas que sólo la fuerza. El ejercicio del poder cede ante recursos más sutiles y, acaso, sofisticados. Hay un ejercicio del poder “... al margen muchas veces de su correlato ético". ${ }^{18}$

Sigamos con la escena descrita arriba: a la par de los personajes, aparece el castigo (la muerte) y el premio (la protección). Asimismo, el miedo se apodera no sólo de Zaldívar sino de Aguirre, “... tienen miedo los que mandan y tienen miedo los que obedecen". ${ }^{19}$ Retomemos una idea más amplia al respecto:

14. Martín Luis Guzmán, La sombra del caudillo. Versión periodística.

15. Nótese que el título de esa entrega hace referencia con claridad al subtítulo de El Universal, y el contenido de la misma es una copia casi literal de los boletines de prensa que emitieron, por separado, Plutarco Elías Calles y Álvaro Obregón sobre la muerte de Serrano y la rebelión de Arnulfo R. Gómez.

16. Fernando Curiel, "Martín Luis Guzmán. Las dos versiones de La sombra del caudillo”, La Jornada semanal.

17. Christopher Domínguez Michael, “Martín Luis Guzmán: el teatro de la política”, Vuelta, p. 27.

18. Fernando Ayala Blanco, Reflexiones sobre hermenéutica, arte y poder, p. 82.

19. Idem. 
... el poder, sabedor de contar con el espontáneo y sincero consenso de los sujetos a él sometidos, comenzará a perder el miedo a posibles revueltas y a renglón seguido dejará de sentir la necesidad de imponer su voluntad por la fuerza. Por otro lado, los súbditos, sintiéndose menos aterrorizados por los gobernantes, empezarán a obedecer al poder con mayor espontaneidad y simpatía. ${ }^{20}$

\section{Los nombres}

¿Quién es quién en La sombra del caudillo? El mismo Guzmán dijo: el caudillo es Álvaro Obregón y se encuentra retratado físicamente, aunque no aparece con un nombre específico. Ignacio Aguirre, el secretario de Guerra, es la suma de Adolfo de la Huerta y del general Francisco Serrano; sin embargo, la descripción física no corresponde a ninguno de los dos, aunque mantiene alguno de los hábitos y gustos de este último, como la preferencia por el cognac Henessy. Aguirre es el típico representante de los generales de la época, joven sibarita y poco honesto, aunque franco, inteligente y correcto. ${ }^{21} \mathrm{Al}$ adentrarnos en la novela, la aproximación más notoria se establece entre Serrano y Aguirre.

Por su parte, el secretario de Gobernación, Hilario Jiménez, es Plutarco Elías Calles. Protasio Leyva es el general Arnulfo Gómez, Jefe de las Operaciones en el Valle y Comandante de la plaza. Encarnación Reyes es el militar veracruzano Guadalupe Sánchez, uno de los principales jefes en la rebelión delahuertista. Emilio Olivier Fernández representa a Jorge Prieto Laurens, dirigente del Partido Cooperativista Nacional y del Bloque Radical Progresista de la Cámara de Diputados, exalcalde de la Ciudad de México y gobernador electo de San Luis Potosí (aunque desconocido por el gobierno central, causa principal de la asonada delahuertista).

Eduardo Correa es Jorge Carregha, quien fuera alcalde interino de la Ciudad de México y hombre de confianza del diputado Olivier Fernández. Jacinto López de la Garza, quien fue general y diputado por el Partido Radical Progresista, consejero y Jefe del Estado Mayor de Encarnación Reyes y Jefe de las Operaciones Militares en el estado de Puebla, es el general tamaulipeco José Villanueva Garza. Ricalde es Luis N. Morones, líder de la Confederación Regional Obrera Mexicana, descrito como inteligente, antipático y monstruoso. En la novela, Ricalde es atacado por Olivier Fernández. Algo parecido ocurrió en la Cámara de Diputados

20. Guglielmo Ferrero, El Poder. Los genios invisibles de la ciudad, p. 57.

21. Luis Leal, “La sombra del caudillo', Roman à Clef”, The Modern Language Journal, p. 16; Guillermo Fárber, Francisco R. Serrano: un héroe desconocido; Pedro Castro, A la sombra de un caudillo. Vida y muerte del general Francisco R. Serrano. 
entre Morones y Prieto Laurens el 26 de agosto de 1922: "Prieto Laurens llamó [...] a Morones un insolente embaucador que ya no puede cargar la escalera del electricista porque se le mancharían sus trajes y le estorbaría su poderoso automóvil”. ${ }^{22}$

López Nieto es Antonio Díaz Soto y Gama. Prieto Laurens dijo de él: "Son desenmascarados hoy en la Cámara de Diputados los líderes agraristas y laboristas [...] el Lic. Antonio Díaz Soto y Gama, cuando Huerta, siguió disfrutando un puesto que le dio Madero ...”23 El capitán Felipe Cahuama, antiguo y fiel asistente del general Aguirre, es Ernesto V. Méndez, llamado por sus amigos, en la vida real, “Cahuama”. Él es la única persona a quien el autor presenta en la novela con el mismo nombre, en este caso, sobrenombre, que llevó en vida. El general Catarino Ibáñez, a la sazón gobernador del Estado de México, antiguo repartidor de leche a domicilio, luego convertido en gran hacendado, representa al general Abundio Gómez, gobernador mexiquense de 1921 a 1924. Conviene precisar que el gobernador de Morelos en 1927, que aprehendió a Serrano y a sus compañeros, era Ambrosio Puente, ya que la novela se desarrolla en Morelos, mientras que los sucesos reales tuvieron lugar en el Estado de México. Paquita Arévalo, la joven actriz madrileña amiga de Aguirre, tal vez sea la artista llamada Delia: "Por la noche se ve en el Teatro Lírico a un presidenciable, el general Francisco R. Serrano, abrazado ebrio a una artista llamada Delia, acompañado de los generales José Gonzalo Escobar y Eugenio Martínez". ${ }^{24}$

Finalmente, el único personaje que no está tomado de la realidad es Axkaná González - alter ego del autor-, encarnación de los valores e ideales puros de la Revolución: “... diputado recto, sincero y concienzudo, representa la pequeña minoría de políticos nacionales que permanecían fieles al ideario de la revolución y que, a pesar de la corrupción de la administración, mantenían su propósito de seguir normas honradas ...”25

\section{La tragedia}

La novela es una tragedia: el padre y los hijos, el caudillo y los generales hermanos que se asesinan. ${ }^{26}$ Es la recreación de las divisiones y venganzas entre los grupos emanados de la Revolución. La política como una

22. Luis Leal, op. cit., p. 20.

23. Idem.

24. Idem.

25. Helen Phipps Houck, “Las obras novelescas de Martín Luis Guzmán”, Revista Iberoamericana, p. 147.

26. Christopher Domínguez Michael, op. cit., p. 27. 
actividad maligna. Casi todas las conductas que denigran a la cultura y a la ética aparecen: nepotismo, corrupción, oportunismo, tortura, homicidio. Veamos: se hace evidente la corrupción del ministro de Guerra al aceptar el soborno de una empresa trasnacional; el candidato, apoyado por el Caudillo, aparece, de súbito, como dueño de la hacienda más grande del norte de México, y Catarino Ibáñez, que pasó de ser un humilde repartidor de leche a potentado ganadero. ${ }^{27}$

Plutarco Elías Calles, en la época del gobierno de Emilio Portes Gil, quiso prohibir la circulación de la novela, editada en España por EspasaCalpe. Convencido por Genaro Estrada, entonces secretario de Relaciones Exteriores, desistió de ello. A pesar de la intervención del canciller, Calles, haciendo gala de su poder como "Jefe Máximo", condicionó la circulación del libro: la editorial vería suprimida su agencia en México si editaba otra historia de Guzmán sobre algún tema posterior a 1910. ${ }^{28}$ Con esta espada de Damocles, Guzmán se dedicó a escribir sobre piratas, corsarios y héroes de la Independencia. En el año de 1938, la editorial Botas hizo una edición mexicana de La sombra del caudillo, situación que es favorecida por la expulsión del país de Calles por Lázaro Cárdenas.

Los políticos asesinados el 3 de octubre fueron: generales Francisco R. Serrano, Carlos A. Vidal, Miguel Ángel Peralta y Daniel Peralta, mayor Octavio R. Almada, capitán Ernesto V. Méndez (Cahuama), licenciados Rafael Martínez de Escobar y Otilio González, Antonio Jáuregui, Carlos Ariza, Alonso Capetillo, José Villa Arce, Augusto Peña y Enrique Monteverde. El licenciado Francisco J. Santamaría logró huir, episodio que corresponde a la escapatoria en la novela de Axkaná González; no obstante, hay una discrepancia: mientras Axkaná se escapa después de herido, el licenciado Santamaría huyó cuando los prisioneros eran conducidos del Hotel Bellavista a la Jefatura de las Armas de Cuernavaca. ${ }^{29}$ Axkaná González logró salvarse porque fue levantado del camino por el primer secretario de la Embajada de Estados Unidos en México, el señor Winter. Es cierto que a la hora del fusilamiento pasó, o quiso pasar, un automóvil procedente de la capital de Morelos, en el cual venían algunos funcionarios de la embajada de aquel país. ${ }^{30}$

27. Alejandro Maldonado Aguirre, El delito y el arte. Invitación a la criminología, pp. 73-74.

28. Jorge von Ziegler, “Tres libros históricos de Martín Luis Guzmán”, Revista de la Universidad de México, p. 56.

29. Luis Leal, op. cit., p. 21.

30. Idem. En el libro Yo fui Plutarco Elías Calles. La versión jamás contada de Alfredo Elías Calles, basado en las memorias de su abuelo, el "Jefe Máximo", y en documentos de la época, la versión que se da sobre Huitzilac es en totalidad distinta a la señalada por Martín Luis Guzmán. Mientras Calles dice que actuar contra Serrano correspondió a una decisión de Estado, ya que se trataba de una rebelión, Guzmán refiere que fue un cobarde asesinato de un adversario político. La "lucha” por la "verdad histórica” continúa. 
No sólo el libro causó polémica, sino también la posterior película filmada en 1960 -15 años después de que el último presidente militar terminara su mandato- con ese mismo nombre y estrenada el 25 de octubre de 1990 en la sala Gabriel Figueroa, en la Ciudad de México, lo que hizo que se le conociera como "la película maldita" del cine mexicano. La dirección corrió a cargo de Julio Bracho, y el guión fue escrito por Jesús Cárdenas, Martín Luis Guzmán y Bracho. Finalmente, el reparto se integró por: Tito Junco (Ignacio Aguirre), Tomás Perrín (Axkaná González), Carlos López Moctezuma (Emilio Olivier Fernández), Miguel Ángel Ferriz (El Caudillo) e Ignacio López Tarso (Hilario Jiménez).

Un veto militar que consideraba inadecuada la proyección de cuestiones históricas comprometedoras y el dicho del secretario de la Defensa, general Agustín Olachea, de que la película denigraba al ejército, son algunas de las respuestas a la imposibilidad de su proyección inmediatamente después de haber sido finalizada, aunque no está de más señalar que durante las grabaciones se contó con apoyo para el uso de instalaciones oficiales, como el Castillo de Chapultepec o la Cámara de Diputados, actual sede de la Asamblea Legislativa del Distrito Federal.

El presidente Adolfo López Mateos, amigo de Guzmán, vio con buenos ojos el proyecto. Una vez que el guion fue aprobado por la Secretaría de Gobernación, el Banco Cinematográfico aportó los fondos correspondientes. La película se rodó del 4 de febrero al 18 de marzo de 1960. En junio de ese año, se realizó la premier y un mes más tarde recibió el premio a la mejor dirección del Festival Internacional de Cine de Karlovy Vary, uno de los más antiguos del mundo, que se realiza en la República Checa. Faltaba su presentación al gran público, pero en vísperas de su exhibición, la Secretaría de Gobernación la prohíbe, requisa las copias y retira los carteles publicitarios. ${ }^{31}$

\section{Aproximaciones finales: la sombra no desaparece}

Martín Luis Guzmán, el gran maestro de los novelistas mexicanos antes de la aparición de Juan Rulfo, empleó la literatura como una forma de denuncia pero, sobre todo, como una herramienta de análisis. Fue a la guerra, al igual que Stendhal, para observar los grandes "espectáculos" humanos. Su verdadero campo de acción se encontraba en la arena política. Su obra fue producto de dos hechos: el ético y el cultural. En el ético radicó la conciencia que tuvo de la tremenda realidad mexicana. Por

31. Pedro Castro, op. cit., pp. 254-255. 
lo que respecta al segundo, Guzmán reunió en sus escritos dos disciplinas: la que se aprende en los libros y la que se adquiere en el contacto con el pueblo. ${ }^{32}$

Si Los de abajo de Mariano Azuela se centra en el punto de vista de los desfavorecidos, La sombra del caudillo se enfoca desde "los de arriba": el poder, sus vicios y sus máscaras. Un mérito más: fue la primera novela de la Revolución hecha gobierno. Guzmán convirtió al movimiento armado de 1910 en el tema de su obra. Además, se volvió en

... la piedra de toque para que otros novelistas de la segunda mitad del siglo XX, como Juan Rulfo, Carlos Fuentes, Elena Garro o Jorge Ibargüengoitia, por mencionar sólo a los más destacados, continuaran la exploración literaria sobre los impredecibles efectos y consecuencias que el movimiento revolucionario mexicano traería a la historia de nuestro país. ${ }^{33}$

Guzmán mostró, mediante sus virtudes (capacidad de comprensión de la naturaleza humana, de entendimiento de las motivaciones políticas, memoria fotográfica, claridad en la expresión y cercanía privilegiada con los revolucionarios), las verdaderas raíces del sistema político posrevolucionario. ${ }^{34}$ La sombra del caudillo, como narración del poder tiene dos correlatos: 1 . El ético-estético y 2. El de la libertad. Con relación al primero, "No solamente responde a una normatividad que limita la acción, sino que puede insertarse en un proceso de expresión de la misma voluntad de poder", ${ }^{35}$ y sobre la libertad, entendida como la

... capacidad de autodeterminación, consciente y responsable, el ejercicio del poder es el que la condiciona en una doble vía: como relación activa (a más poder, más capacidad de determinación y dominio sobre la otredad), y como relación pasiva (a menos poder, menos capacidad de determinación y dominio por sí mismo). ${ }^{36}$

De manera que los generales Aguirre y Jiménez, en la búsqueda de la presidencia de la República, ordenaron la vida de los otros, para que sirvieran a sus propósitos. Aquí conviene preguntarnos si los "vencedores",

32. Ermilo Abreu Gómez, "Martín Luis Guzmán: crítica y bibliografía”, Hispania, p. 70.

33. Hernán Lara Zavala, “Las enseñanzas de Martín Luis Guzmán”, La Jornada semanal.

34. Helen Phipps Houck, op. cit., p. 144.

35. Fernando Ayala Blanco, Reflexiones sobre hermenéutica, arte y poder, p. 55.

36. Idem. 
en la novela y en la vida real, tuvieron fuerza o poder. Para Elías Canetti, la fuerza es más próxima que el poder, ya que es más coercitiva e inmediata. No obstante, cuando la fuerza tiene una duración mayor y es más sutil se convierte en poder. ${ }^{37} \mathrm{El}$ recurso a las armas por parte de los hilaristas demuestra que tuvieron fuerza y Aguirre conquistó el poder.

Guzmán, mediante su narrativa, no sólo describe actos, sino que reconstruye escenarios y, a través de sus personajes, transmite los sentimientos de los que estuvieron ahí. ${ }^{38}$ Siguiendo a Cesare Pavese:

... es una leyenda el considerar que los poetas y narradores se dirigen al hombre abstracto. Hablan al individuo de una época y situación, al individuo que siente determinados problemas y busca a su manera su solución sobre todo cuando lee novelas. Para entender las novelas será necesario situarse en la época, y plantearse sus problemas. ${ }^{39}$

Guzmán logró reconstruir el ambiente trágico que envuelve al personaje de Ignacio Aguirre.

El efecto más visible de la literatura es el de despertar en los lectores -con la ayuda de Hermes, el dios que traduce, traslada y transcribe el conocimiento; en suma, el que media entre quien pronuncia el discurso y quien lo recibe- ${ }^{40}$ una conciencia de las deficiencias del mundo en el que viven y eso es, esencialmente, político. Es una manera de formar ciudadanos críticos que estarán en un estado de perpetua desconfianza, porque están cotejando, de forma inconsciente, aquello que han leído con su experiencia vital, ${ }^{41}$ y esto es lo que genera la lectura de la obra de Martín Luis Guzmán, conspicuo develador de las leyes formales y de los tratos informales de la política, la cultura y la moral mexicanas, ${ }^{42}$ y juez implacable del poder.

\section{Bibliografía}

ABREU GÓMEZ, Ermilo. "Martín Luis Guzmán: crítica y bibliografía”,

37. Ibid., p. 56.

38. Rosa María Lince Campillo, "Narraciones literarias, textos que permiten comprender un pueblo", Estudios Políticos, p. 12

39. Ibid., p. 32.

40. Fernando Ayala Blanco, op. cit., pp. 21-22.

41. Mario Vargas Llosa, Literatura y política, pp. 53 y 55.

42. Fernando Curiel, La querella de Martín Luis Guzmán, p. 30. 
Hispania. Vol. 35, núm. 1, 1952.

AYALA BLANCO, Fernando. "Reflexiones en torno a la relación arte y poder a la luz de la hermenéutica", Estudios Políticos. Núm. 30, 2013.

--- Reflexiones sobre hermenéutica, arte y poder. Universidad Nacional Autónoma de México, México, 2014.

BRUSHWOOD, John S. México en su novela. Una nación en búsqueda de su identidad. Fondo de Cultura Económica, México, 1973.

CAPETILLO, Alonso. La rebelión sin cabeza. Génesis y desarrollo del movimiento delahuertista. Editorial Botas, México, 1925.

CASTRO LEAL, Antonio. La novela de la Revolución mexicana. Tomo I, Secretaría de Educación Pública/Aguilar, México, 1965.

CASTRO, Pedro. A la sombra de un caudillo. Vida y muerte del general Francisco R. Serrano. Plaza y Janés, México, 2006.

CURIEL, Fernando. "Martín Luis Guzmán. Las dos versiones de La sombra del caudillo", La Jornada semanal, núm. 772, suplemento de La Jornada. México, 20 de diciembre de 2009, disponible en: http://www.jornada.unam.mx/2009/12/20/sem-fernando.html.

. La querella de Martín Luis Guzmán. Universidad Nacional Autónoma de México, México, 2014.

DOMÍNGUEZ MICHAEL, Christopher. "Martín Luis Guzmán: el teatro de la política”, Vuelta. Vol. 11, núm. 131, 1987.

ELÍAS CALLES, Alfredo. Yo fui Plutarco Elías Calles. La versión jamás contada. Suma de Letras, México, 2012.

FÁRBER, Guillermo. Francisco R. Serrano: un héroe desconocido. El Colegio de Sinaloa, México, 1996.

FERRERO, Guglielmo. El Poder. Los genios invisibles de la ciudad. Tecnos, Madrid, 1998.

GARCIADIEGO, Javier. "Los intelectuales y la Revolución mexicana”, Carlos Altamirano (dir.), Historia de los intelectuales en América Latina. II Los avatares de la "ciudad letrada" en el siglo XX. Katz Editores, Buenos Aires, 2010.

GONZÁLEZ CASANOVA, Manuel. El cine que vio fósforo: Alfonso Reyes y Martín Luis Guzmán. Fondo de Cultura Económica, México, 2003.

GUTIÉRREZ VEGA, Hugo. "Notas sobre la novela de la Revolución (III de VI)”, La Jornada semanal, núm. 901, suplemento de La Jornada, México, 10 de junio de 2012, disponible en: http://www. jornada.unam.mx/2012/06/10/sem-bazar.html.

GUZMÁN, Martín Luis. La sombra del caudillo. Obras Completas II. Fondo de Cultura Económica/Instituto Nacional de Estudios 
Históricos de las Revoluciones de México, México, 2010. . La sombra del caudillo. Versión periodística. Universidad Nacional Autónoma de México, México, 1987.

LARA ZAVALA, Hernán. "Las enseñanzas de Martín Luis Guzmán”, La Jornada semanal, núm. 772, suplemento de La Jornada, México, 20 de diciembre de 2009, disponible en: http://www.jornada. unam.mx/2009/12/20/sem-hernan.html.

LEAL, Luis. "'La sombra del caudillo', Roman à Clef”, The Modern Language Journal. Vol. 36, núm. 1, 1952.

LINCE CAMPILLO, Rosa María. "Narraciones literarias, textos que permiten comprender un pueblo", Estudios Políticos. Núm. 34, 2015 .

MALDONADO AGUIRRE, Alejandro. El delito y el arte. Invitación a la criminología. Universidad Nacional Autónoma de México, México, 1994.

MORTON, F. Rand. Los novelistas de la Revolución mexicana. Editorial Cultura, México, 1949.

PHIPPS HOUCK, Helen. "Las obras novelescas de Martín Luis Guzmán”, Revista Iberoamericana. Vol. III, núm. 5, 1941.

QUINTANILLA, Susana. "El águila y la serpiente, de Martín Luis Guzmán”, Letras Libres. Núm. 136, 2010, disponible en: http:// www.letraslibres.com/revista/convivio/iv-el-aguila-y-la-serpientede-martin-luis-guzman.

REYES, Alfonso y Martín Luis Guzmán. Fósforo. Crónicas cinematográficas. Consejo Nacional para las Culturas y las Artes/ Instituto Mexicano de Cinematografía, México, 2000.

SALVO AGUILERA, Benjamín. "La sombra de Martín Luis Guzmán”, Cuadernos Americanos. Vol. 1, núm. 73, 1999.

VARGAS LLOSA, Mario. Literatura y política. Fondo de Cultura Económica/Instituto Tecnológico de Estudios Superiores de Monterrey, México, 2005.

ZIEGLER, Jorge von. "Tres libros históricos de Martín Luis Guzmán”, Revista de la Universidad de México. Vol. 47, núm. 497, 1992. ZULETA, Emilia de. Historia de la crítica española contemporánea. Editorial Gredos, Madrid, 1974. 